\title{
The Impact of Political Violence on Urban Morphology: the City of Ramadi / Iraq as a Case Study
}

\author{
Author's Name: Abduallah Noorie Sager Affifliation (German \\ Jordanian University)
}

\begin{abstract}
This study investigates the impact of armed political violence on urban morphology of the Iraqi city Ramadi during (2007-2017). The political violence is a term that refers to violence that prevents or eliminates certain individuals or groups from participating in power by causing psychological, social and physical damage. While urban morphology refers to the study of change in the physical form. Armed Political violence poses a threat to the configuration of cities and urban areas. It restricts the movement and activities of individuals and groups, with economic, social, political and cultural effects. Violence affects cities morphology in three ways. First, concentrations of people have a feature in defending themselves from attackers. Second, the emergence of cities as targets of violence makes people dispersed. Finally, frequently violence targeted the transportation system which increases the effective cost of transportation, which usually increases the demand for density (Glaeser,2001). Over the last years, Ramadi, the capital of Al- Anbar province, has undergone several changes in its morphology as a result of violence.

The aim of this study is to focus on the impact of violence on urbanization, which was caused by the arrest of growth and urban expansion in western Ramadi. The study will be conducted on the Ramadi western neighborhoods, which have been subjected to violence, destruction and change in urban form. An exploratory sequential mixed methods design will be used as a methodology .This study assumes that violence has affected the urban morphology of Ramadi.
\end{abstract}

Keywords: Political violence, urban morphology, cities, urban form, density. 
